\title{
SOULAGES, MICHAUX, MALRAUX Y VIEIRA DA SILVA, AMIGOS E INSPIRADORES DE ZAO WOU-KI
}

\section{SOULAGES, MICHAUX, MALRAUX AND VIEIRA DA SILVA, FRIENDS AND INSPIRERS OF ZAO WOU-KI}

\author{
Satoru Yamada \\ Universidad de Valladolid
}

\section{RESUMEN}

Zao Wou-Ki (1921-2013) fue un pintor chino reconocido internacionalmente. Para alejarse del convencionalismo del arte chino decidió instalarse en París, pero tras conocer la obra de Paul Cézanne y Paul Klee, Zao se reconcilió con la tradición china, con el signo y el qui como elementos clave en su obra.

Cuando llegó a París Zao conoció a muchos artistas emergentes que dejarían huella en la Historia de Arte y que serían impulsores de su propio camino artístico, contribuyendo a la recuperación de sus raíces. Hoy nadie ha abordado en profundidad este nexo, motivo por el cual este trabajo se postula como una investigación pionera en la materia. El hecho de que Zao trabajara con numerosos poetas, tras su colaboración con Henri Michaux, nos remite al principio chino de coincidencia entre el poema y la pintura que subyace en su creación, por lo que, en este artículo, vamos a centrarnos en estudiar su colaboración con los poetas para investigar su arte y vincularlo con estudios filológicos sobre poesía. De otra parte, estudiaremos el concepto de qui en el espacio pictórico chino, ya que Zao recogió la idea de Pierre Soulages, que compartía la idea del espacio y la luz con Zao.

Palabras clave: Zao Wou-Ki, Henri Michaux, Soulages, Vieira da Silva.

\section{ABSTRACT}

Zao Wou-Ki (1921-2013) was a Chinese painter with a universal reputation. Because of the conventionalism of art in China, he decided to settle in Paris. It is known that there he started thanks to the art of Cézanne and Klee, and Zao began to sublimate the Chinese tradition: the sign and the qui as his style in his work, but we can guess that there is something more.

When he arrived in Paris, got to meet many emerging artists who would leave their mark on the History of Art. They must be the pointers of the artistic path. They also helped him to recover his root in his art through collaboration, but there is not much research done on that. The fact that Zao worked to dedicate the works to numerous poets after the collaboration with Henri Michaux reminds us of the Chinese aesthetic coincidence between poem and painting. We analyze his collaborations with poets to investigate such a concept in his art. Another part to develop the qui, the Chinese pictorial space, we consider that Zao took the spark from Pierre Soulages. Soulages shared the idea of space and light with Zao, so his dialogues are analyzed.

Key words: Zao Wou-Ki, Henri Michaux, Pierre Soulages, Vieira da Silva. 


\section{INTRODUCCIÓN}

En este trabajo investigamos las referencias estéticas chinas de carácter tradicional utilizadas por Zao Wou-Ki (pinyin, Zhào Wújí) 1921-2013), un pintor chino que, con el tiempo, adquirirá la nacionalidad francesa y se decantará por estéticas compartidas y colaboraciones con sus amigos pintores. Es un pintor abstracto que pinta basándose en su propia interpretación de la estética china. Aunque hay estudiosos del arte de Zao Wou-Ki, los investigadores se han acercado a su arte a través de las influencias de Paul Cézanne y Paul Klee, y no hay estudios profundos sobre los planteamientos estéticos enraizados en el taoísmo, sobre el concepto de $q u i$, ni sobre la intrínseca unión entre poema y pintura. Ahondar en las raíces estéticas de Zao nos ayudará a entender mejor su plástica. Para destacar las peculiaridades basadas en la estética china del arte de Zao, analizamos, por contraste y aproximación, las obras de sus amigos pintores occidentales, con quienes trabajó en un constante estímulo mutuo a través de la tertulia y otras actividades. Algunas de las claves o las pistas para entender el arte de Zao podemos encontrarlas en ellos.

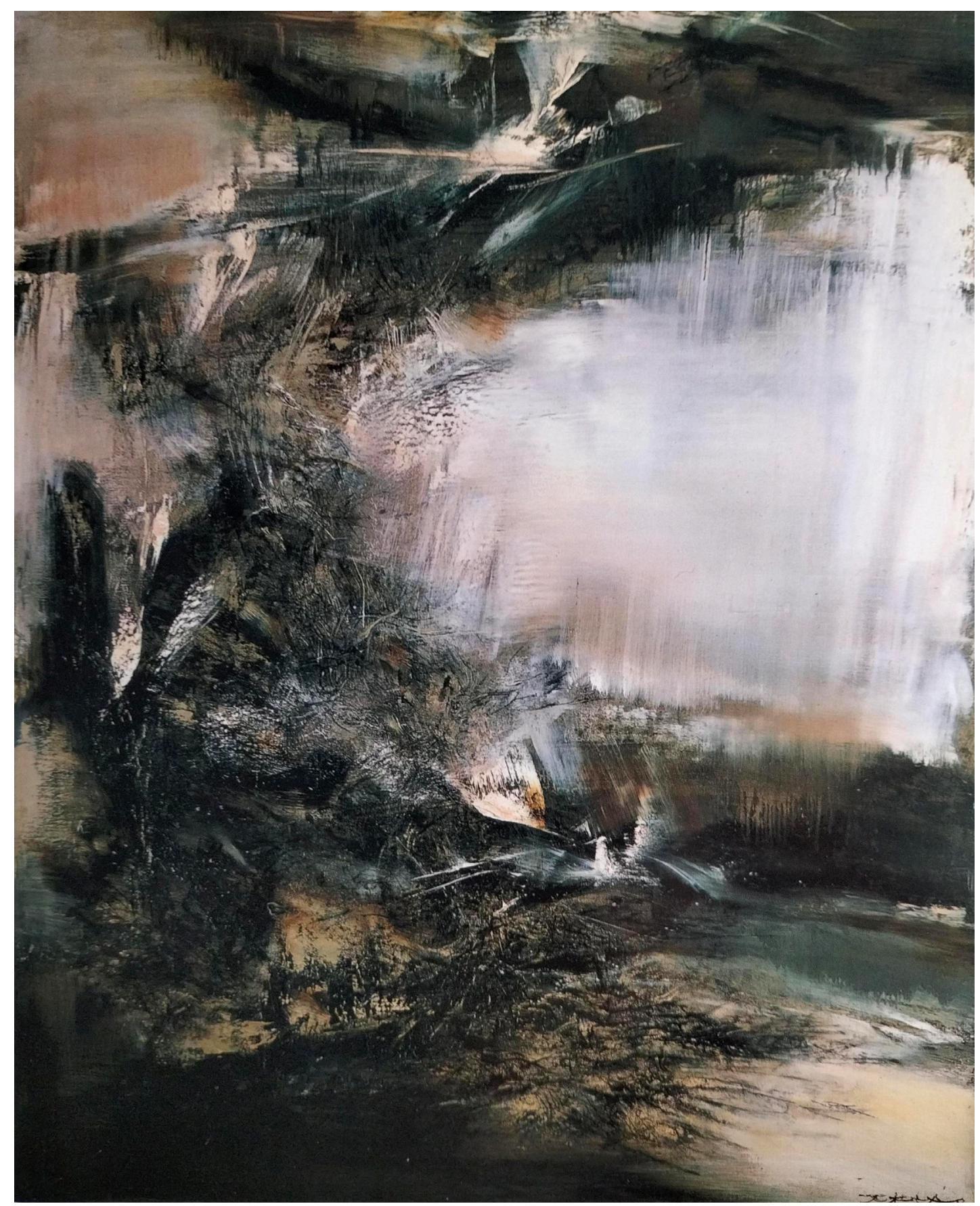

Fotografía 1. “17. 01. 66”. Óleo en lienzo, $33 \times 32,5 \mathrm{~cm}, 1949$, colección privada 
También hemos de tener en consideración que después de la concertación del Tratado de Versalles en 1919, que suponía la cesión a Japón por parte de China de determinados privilegios comerciales, se produjo un fuerte interés a favor de la divulgación y aceptación del arte occidental en China, considerando que la cultura tradicional era un síntoma de la debilidad del país. Muchos pintores prestaron atención al arte occidental, y con la ocupación militar japonesa de 1937 el arte chino fue reprimido y se convirtió en un arte considerado pesimista. En este contexto histórico, podemos citar como ejemplos a Xu Beihong (1895-1953) quien estuvo en París para formarse entre 1919 y 1927, quien a su regreso a China enseñó lo aprendido en la universidad; o Pan Yulian (1920-1977) quien se instaló en la capital francesa en 1937, permaneciendo allí hasta el final de su vida (Fernández del Campo y Sanz Giménez, 2011: 21-25).

Zao nace en Pekín en una familia de rango social alto. En su infancia se traslada a Nantung, donde realiza sus estudios primarios, y es aceptado en la Escuela de Bellas Artes de Hangzhou en 1935, donde permanece hasta 1941. Estudia arte, pero la enseñanza académica le decepciona por su academicismo, tal como Zao mismo manifiesta: "la pintura china dejó de ser creativa a partir del siglo XVI, y a partir de entonces, los pintores no hicieron más que copiar lo que la gran tradición Han y Song había inventado.” (Zao y Marquet, 2004: 24). Siendo joven, Zao Wou-Ki leyó el ensayo Sobre la contradicción (1937) escrito por Mao Tse Tung, fundador de la República Popular China en 1949. Mao propone que todo movimiento y vida es el fruto de las unidades de una contradicción. Zao pensaba que el arte también tiene que ser una "unidad de los contrarios", por eso no estaba satisfecho con la enseñanza de la Escuela que sólo se basaba en la tradición. Anhelaba encontrar la esencia del arte y buscó en el arte occidental.

La mayor parte de las obras del joven Zao realizadas en China se destruyeron o están pérdidas, de forma que tenemos que imaginar el arte de esta época temprana a través de las escasas obras subsistentes. Cuando tenía 20 años, sus obras muestran una aproximación a los impresionistas, a Picasso y Matisse. A pesar de su pincelada delicada todavía no tenía claro el camino que debía seguir. Por la necesidad de cambiar de ambiente, se trasladó a Francia en 1948, donde tenían lugar los nuevos movimientos artísticos vanguardistas. Este traslado fue determinante en su carrera.

Después de su llegada a París realizó numerosos recorridos por los museos parisinos y las galerías, descubriendo a muchos nuevos artistas. Curiosamente, cada vez que conocía mejor el arte de los occidentales, este le recordaba más su propia raíz y la tradición china.

Los descubrimientos más importantes para el pintor chino fueron Cézanne y Klee. Ante las obras de paisaje de Cézanne, en las que el artista captaba el ambiente de las montañas, Zao recordó la aproximación tradicional de estilo chino a la naturaleza. Zao empezó a buscar la manera de captar el ambiente condensando los objetos en una geometría simplificada, en una obra de estilo jeroglífico, interpretándolos según su propio punto de vista.

Otro momento decisivo fue 1951, cuando descubrió el arte de Klee. Descubrió un mundo íntimo e interior en los óleos del pintor suizo. Tal como el propio pintor reconoció, empezó entonces a seguir el camino del artista suizo. Después de observar la obra de Klee encontró la manera de expresar lo que, como chino, llevaba dentro. Desde ese momento en sus óleos aparecieron muchos signos a modo de jeroglíficos chinos inventados por él, sí mismo, como si flotaran en un mundo tridimensional.

Zao profundizó en ese estilo y, finalmente, superó la influencia de Klee. Llegó a crear un lenguaje lleno de la energía vital qui que inspira la cosmología china. En él, ni siquiera aparecían los signos. La fama le llegó con sus obras dominadas por el efecto del qui. Sin duda, Cézanne y Klee son claves imprescindibles para entender el arte de Zao, pero, es preciso profundizar en las interacciones con los artistas amigos de Zao Wou-Ki para entender su arte. Desde la aparición del impresionismo, París fue una meca de artistas donde nacieron muchas corrientes pictóricas innovadoras.

Cuando Zao llegó a París, la ciudad vivía entre las ruinas causadas por la Segunda Guerra Mundial. Los parisinos estaban sumidos en el existencialismo de Sartre, en búsqueda de la condición humana, la libertad, la responsabilidad individual y las emociones. Zao pudo contemplar el modo en el que el existencialismo cobró vida en las artes plásticas con la aparición del informalismo, nombre y concepto que comienzan a ser definidos por Michel Tapiè alrededor de 1951. Artistas como Dubuffet, Fautrier, Henri Micheaux, Hans Hartung 
o Wols buscaban a través de la materia y con sus trazos evocar el gesto pictórico cargado de energía y sentimiento, y buscar nuevas vías de expresión artística que dejaran aflorar la subjetividad individual y el abismo interior. Todos ellos, junto a sus admirados maestros clásicos, dejaron su huella en el arte de Zao.

El pintor chino recién llegado a París se encontraba desorientado en el contexto cultural occidental. Esto, lo cotidiano, le requirió un gran esfuerzo, al que tenía que sumar el trabajo de su propia búsqueda artística. Zao trabajó sin escatimar esfuerzos-

Entre 1948 y 1955, coincidiendo con su llegada a París, su trabajo se halló en una encrucijada al confrontar su trayectoria figurativa con las tendencias absolutamente abstractas que estaban en plena ebullición. Fue gracias a la ayuda, consciente o inconsciente, de sus amigos como superó esta difícil situación anímica y profesional, y finalmente consiguió crear una obra sólida de gran reputación y sumamente personal.

Por eso si analizamos el arte de sus amigos, los diálogos y las colaboraciones entre ellos y Zao, podemos comprender la evolución de su arte más profundamente y, desde otro punto de vista, más allá de la estudiada influencia de Cézanne y Klee. Como hemos mencionado más arriba, inspirado por el arte de estos dos grandes artistas Zao recuperó tradiciones propias como la de la coincidencia entre el poema y la pintura y su vinculación con la escritura pictográfica y el concepto de qui o aliento espiritual.

En relación con la primera analizaremos la colaboración de Henri Michaux con Zao, el primero de una larga nómina de poetas con los que trabajaría después el pintor chino, porque fue seguramente gracias a él que recordó el principio tradicional chino de coincidencia entre el poema y la pintura.

Con relación al principio del aliento espiritual, Zao encuentra en la obra de Pierre Soulages, algo muy similar y afín, hasta tal punto que entender el arte de Soulages, nos facilitará el entendimiento del arte de Zao. El aliento espiritual del arte de Zao Wou-Ki es la expresión del ambiente qui. En la pintura a la tinta china, el vacío donde no hay ningún trazo no es literalmente vacío, sino que debe tener la sensación de un aliento espiritual, la energía

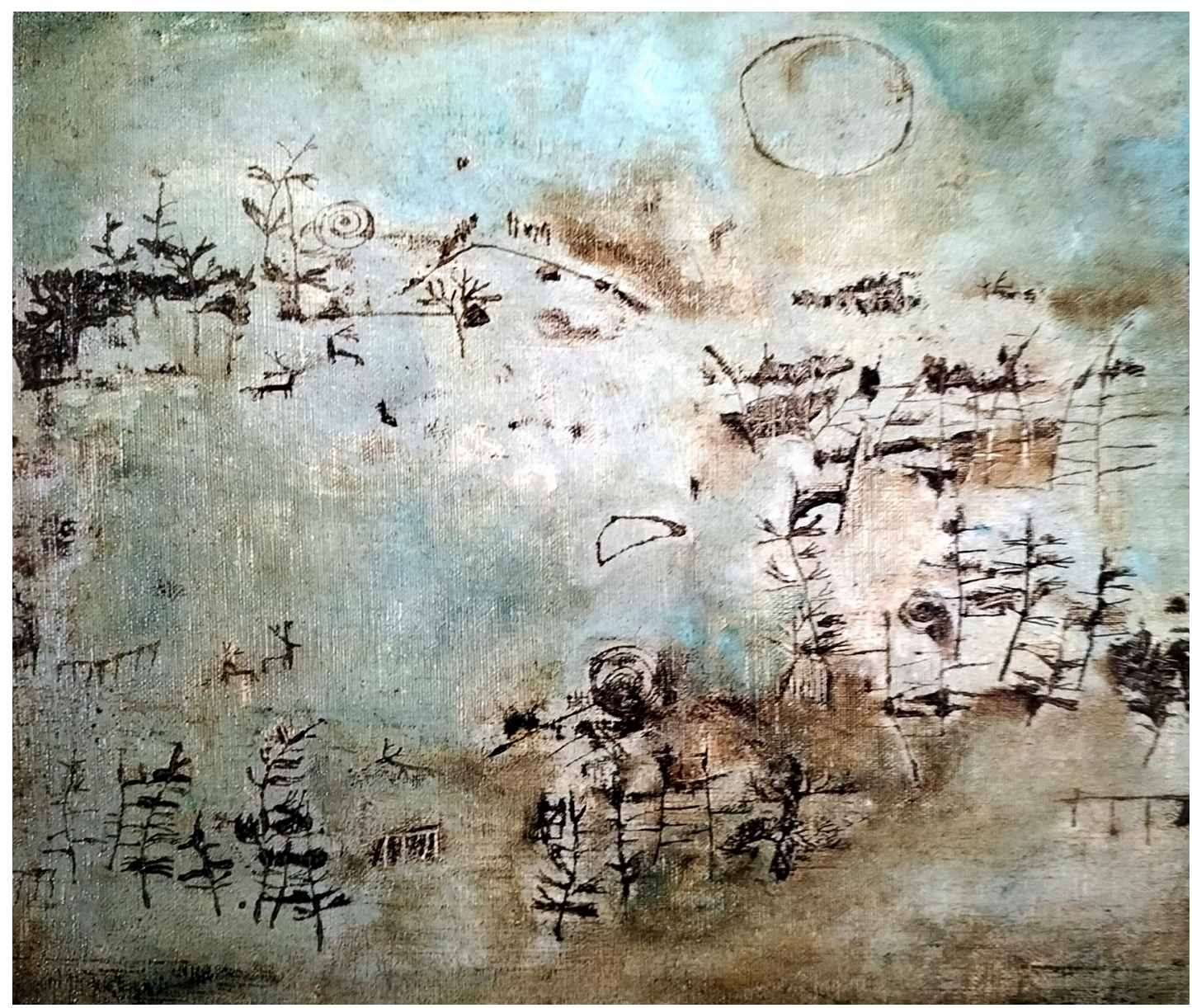

Fotografía 2. "Paysage vert (Paisaje verde)". Óleo en lienzo, $33 \times 32,5$ cm, 1949, colección privada 
vital. Después de despertar el interés por su tradición, el mundo pictórico de Zao Wou-Ki, empezó a llevar la sensación de la expansión de aire por todas partes. Zao fomentó el interés de la creación del nuevo espacio pictórico basado en el qui.

\section{ANÁLISIS DEL ARTE DE ZAO WOU-KI}

Para analizar la creación de Zao Wou-Ki seguiremos la evolución cronológica de algunas de sus obras desde su llegada a París.

Una de sus primeras pinturas es Paysage vert (Fotografía 2) donde gracias al posicionamiento de la luna, la línea de la cresta de la colina y la colocación de los árboles en la composición podemos entender la representación cómo un paisaje. Los árboles y los animales están esquematizados de modo muy sencillo como si estuvieran dibujados por niños: una línea vertical simple como tronco, pero sólida con las líneas horizontales como ramas, cruzadas con el tronco. Los árboles están realizados como un símbolo, como sacado del proceso de creación de un logograma, tal como se hace en la escritura japonesa y la china de árbol (木). Los animales también están hechos con unas líneas muy simples y abreviadas, de modo que por los cuernos podemos identificarlos con ciervos. En la parte de arriba está pintado el sol, pero como un mero círculo. Finalmente podríamos decir que todos los elementos de la obra están muy simplificados al modo de un jeroglífico.

En 1951 Zao se enfrentó directamente a las obras el arte de Paul Klee y se quedó impresionado. A partir de ese momento quedó bajo su influjo generando una serie de creaciones se conocen como "sub-Klee (Zao)". Zao empezó a introducir el signo, a modo de ideograma chino y el qui. Gracias a Klee, la tradición china que quería abandonar se convirtió en un atajo para crear un arte innovador.

La obra "Bateaux dans le chantier naval (Fotografía 3)" está cuajada de líneas finas. Aunque difícilmente se aprecia la forma del mástil del barco, ya no se ven los navíos sino manchas y saturación de las líneas. Como esencia de la embarcación, el pintor dibuja los palos para que sean su símbolo, porque si viéramos sólo triángulos no entenderíamos qué son. La creación de la figura simplificada, sacando la parte esencial y condensándola en una

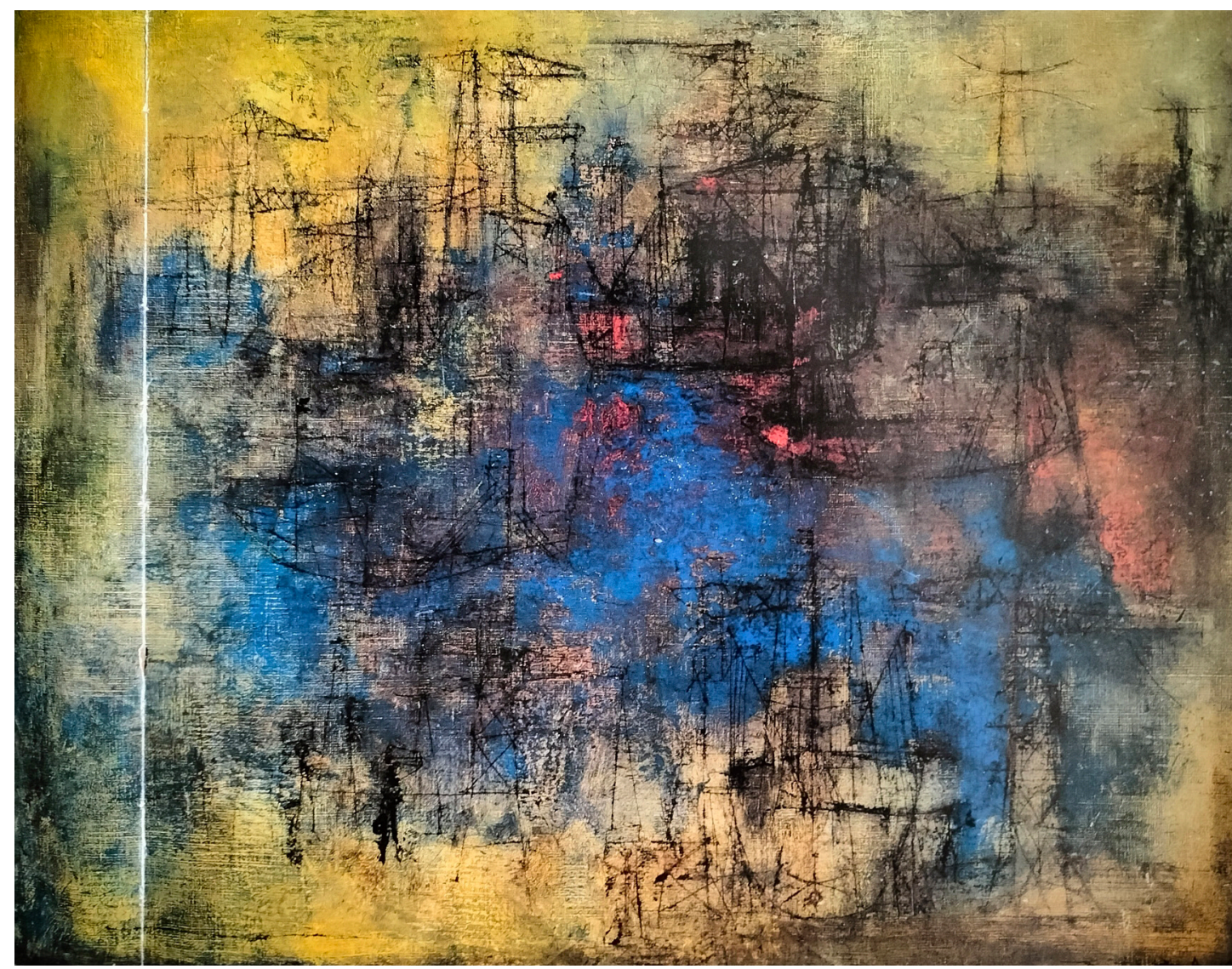

Fotografía 3. “Bateaux dans le chantier naval (Barcos en el astillero)”. Óleo en lienzo, 73 × 92cm, 1951, colección privada 


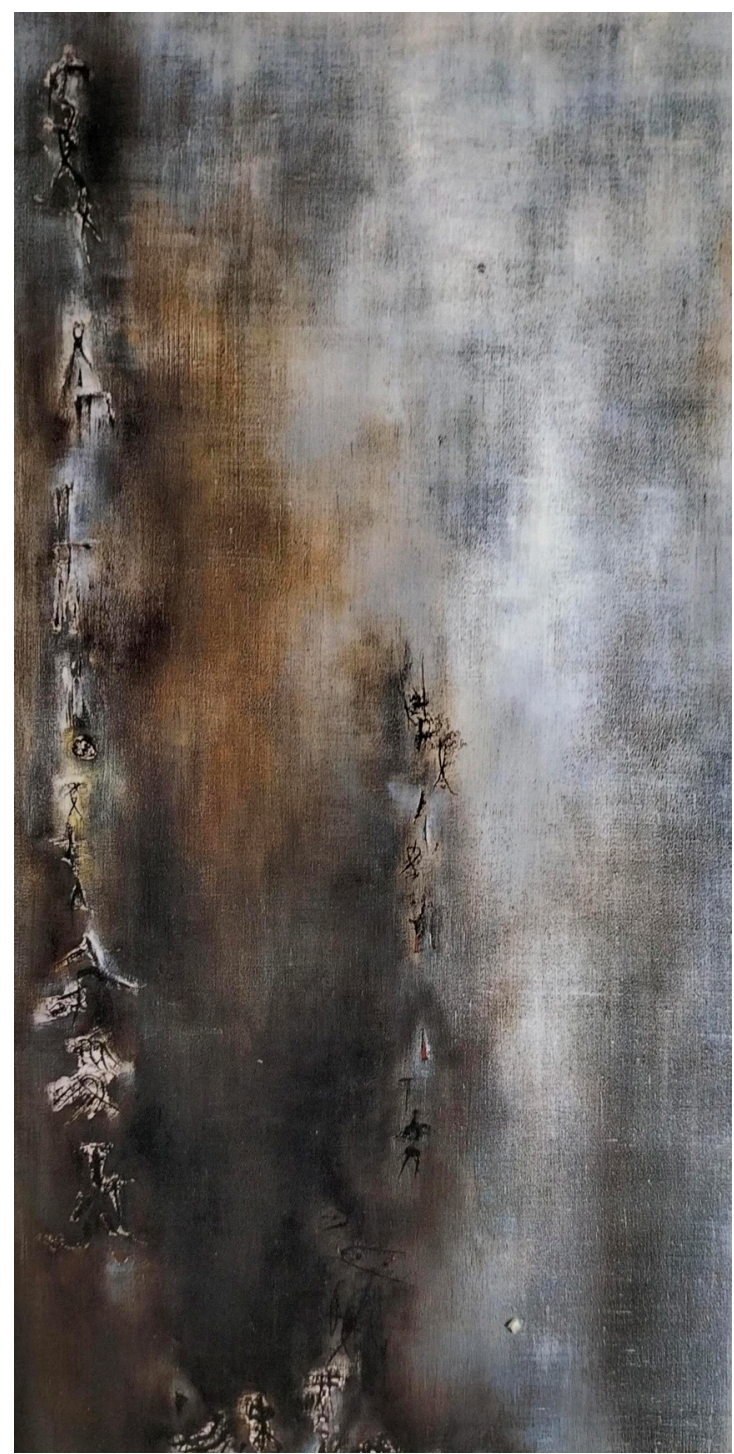

Fotografía 4. "Vent (Viento)" Óleo en lienzo, $195 \times 96,5 \mathrm{~cm}$, 1954. Centro Pompidou geometría simple, está muy probablemente basada en la escritura ideográfica china. Como en la obra de Klee hay muchos objetos simplificados a la manera de signos.

En 1953 el arte de Zao Wou-Ki empezó a evolucionar de un modo muy personal. Las obras se transforman bajo el movimiento de la muñeca, que requiere que todo el cuerpo se involucre en dicho movimiento a través del pincel, tal como los calígrafos chinos dejan que su cuerpo trabaje inconscientemente. Zao Wou-Ki domina cada vez más las técnicas occidentales, conservando en el empleo del pincel la maestría china. En la obra "Vent" (Fotografía 4), en vez de los signos simplificados de los objetos, las "letras" inventadas por Zao se unen formando una cadena. Se ven precipitándose lentamente en el fondo grisáceo generando una sensación de tridimensionalidad, como si estuvieran flotando en el espacio o como si estuvieran cayendo en el mar gris. En el borde inferior de la tela se ven las letras abandonadas como hojas otoñales caídas en la calle.

Se podría considerar que en las piezas de este momento hace su aparición el principio de coincidencia entre la caligrafía y la pintura. Podría hablarse de una estética en la que el poema es la pintura legible, porque cuando se lee el poema, surge el paisaje en el interior de los lectores a través de la visión de los ideogramas. El poema y la pintura son lo

mismo. El concepto procede en cierta medida del uso del mismo material en la caligrafía y la pintura china: papel, pincel y tinta. Además, en China tendía a admirarse la caligrafía más que la pintura, porque se consideraba que la esta había sido cultivada durante muchos más siglos. En realidad, la calígrafa establece el estilo o el concepto metodológico al incorporar los materiales en la creación, en el sentido de considerar al pincel como parte de la mano del calígrafo que se mueve inconscientemente. Por eso, se supone que la pintura a la tinta china es un arte que derivó de la caligrafía. Lógicamente las metodologías del uso de los materiales son casi comunes, por eso surgió la idea de que la caligrafía de poemas y la pintura son dos artes de la misma raíz.

Hay otra razón de la aparición de esta estética. Los chinos expresan su escritura a través de caracteres ideográficos. Los elementos de la escritura derivan de elementos comunes y concretos simplificados, comprensibles por el inconsciente colectivo. Si el calígrafo escribe un poema sobre la naturaleza, se parece a la pintura de tinta china de paisaje. El artista chino, calígrafo o pintor, cuando trata la naturaleza, tradicionalmente realiza la obra para expresar un elogio al tao, a toda la verdad del cosmos. En las obras de caligrafía en las que se trata la gran naturaleza aparecen muchos elementos como la montaña, la roca, la planta, el árbol, los animales, el pájaro y otros seres de la naturaleza que se convierten en verdadera expresión de la naturaleza. Incluso aparecen pinturas en las que se escriben poemas, pero esto no significa que la pintura sea incompleta y que necesite la ayuda de la escritura. La pintura y el poema son independientes, pero si se reúnen, pueden producir un arte innovador potenciándose 


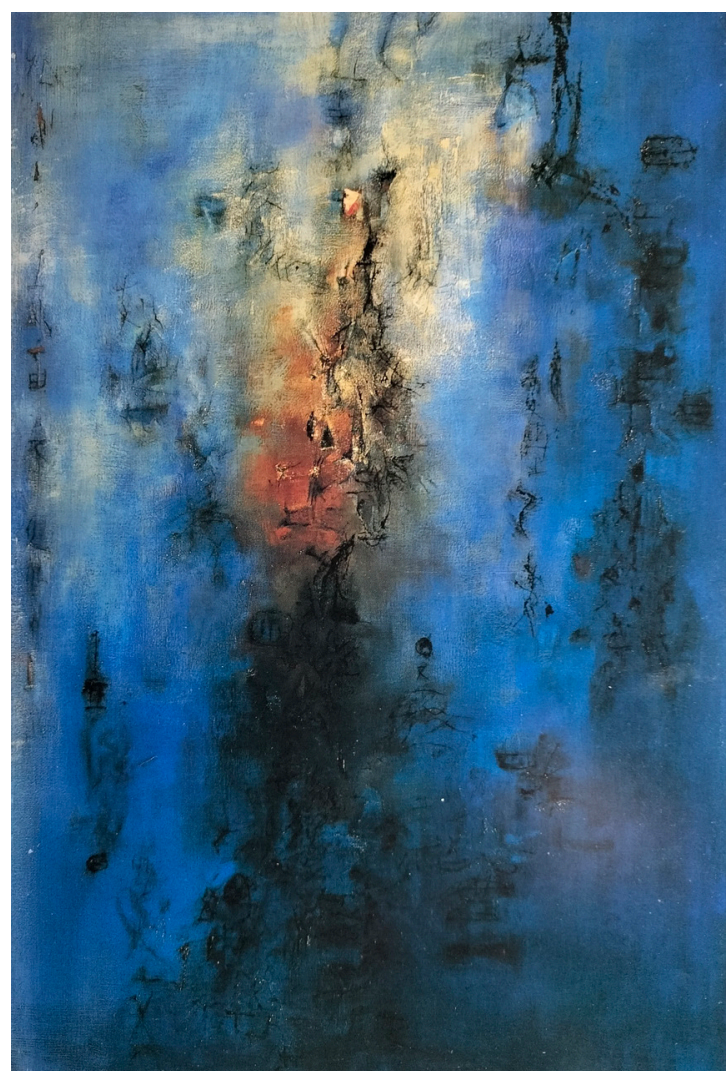

Fotografía 5. “Hommage à Qu Yuan (05.05.55) (Homenaje a Qu Yuan (05.05.55))”. Óleo en lienzo, $195 \times 130 \mathrm{~cm}$. Colección privada mutuamente. Esta idea se ha convertido en una estética dominante en la pintura china, incluidas la zen y la taoísta.

Zao vuelve su mirada hacia este tipo de obras chinas y emplea en sus obras pictogramas que no se corresponden con los actuales, y aunque son inventados, son muy parecidos a los empleados en la escritura de los huesos oraculares. El pintor se refiere a ellas porque recogen una intuición primitiva y mística, y porque además la forma nos retrotrae a la historia de más de veinte siglos. Las letras antiguas tenían un poder mágico, por eso se pueden concebir las raíces fundamentales y básicas de la vida a través de las letras primitivas.

La obra "Hommage à Qu Yuan (05.05.55) (Fotografía 5)" es muy interesante. $\mathrm{El}$ fondo es de un azul más intenso en la parte inferior y, en la parte superior la zona blanca nos da la impresión de una luz mística, confiriendo a la obra una sensación sagrada y sofisticada. El fondo con los tonos distintos de azul y con la combinación del blanco, nos ofrece un sentido de extensión hacia lo lejano como si estuviéramos en el mar, a caballo entre la parte de la luz y la parte totalmente oscura a la que la luz no puede llegar. En la obra la escritura de tipo hueso oracular de Zao se aprecia con dificultad, son ya casi únicamente manchas negras. Los signos van cayendo de forma paulatina, como si flotaran en el espacio. Las obras tienen un carácter común a la caligrafía porque las "letras" de Zao producen la misma impresión que en ésta: flotan en el espacio. Zao introdujo en su cuadro dos elementos de la pintura china interpretados por su particular punto de vista: el espacio pictórico caligráfico y los trazos caligráficos.

Por otra parte, se puede ver como si hubiera una sustancia de los seres primitivos, porque la escritura de tipo hueso oracular del pintor chino responde a los símbolos del prototipo de los seres. Esta pintura capta el momento de la generación de los seres desde el punto de vista de la filosofía de Laozi. Zao empieza a pintar un mundo expansivo lleno de la energía qui, como el momento del Big Bang.

\section{HENRI MICHAUX (1899- 1984) Y LOS POETAS}

Michaux es un amigo de Zao, poeta y pintor belga nacionalizado francés que intentó eliminar el límite entre la poesía y la pintura. En 1925 descubrió a Paul Klee, quedó impactado por su sensibilidad, por eso empezó a pintar. En 1927 comenzó a redactar un "escrito" titulado "Alfabetos". Entre 1927 y 1937 viajó por Asia Oriental. Después de conocer Asia empieza a tomar mescalina para hacer desaparecer su "yo". En 1933 escribió su famoso libro Un barbaro en Asia, en el que recoge la experiencia de su viaje por el Lejano Oriente. Desde los años cuarenta en adelante, la influencia oriental es evidente en su obra en los paisajes brumosos. Después del descubrimiento del zen en los años cincuenta, comenzó a simplificar su material, a restringir las composiciones a gestos plásticos y manchas de pintura. Realizó entonces una serie de obras muy caligráficas en las que hay muchas "letras" inventadas, tal es el caso en "Mouvement" (Fotografía 6). Cada "letra" de la obra tiene una pincelada distinta. El crítico de arte Takiguchi Shūzō escribe:

"(Henri Michaux) Sigue experimentando muchos años para escribir el "signo" 
que surge desde la inconsciencia pura, antes que como pintor profesional, como poeta. Sin embargo, la serie de los dibujos "Mouvement" no solo evoca todo tipo de movimiento humano, sino también se ve como si moviera el prototipo que llegará a ser un ideograma. Las personas de un país donde no se conocen los ideogramas buscan ideogramas vivos, innovadores. Me da la impresión de que Michaux busca el "Clásico de mil caracteres".

En realidad, el trabajo de Michaux es como la búsqueda del alfabeto existente. Por ejemplo, en los veinte ya Michaux realiza muchos dibujos como si escribiera, en unas docenas de líneas, "muchos signos muy misteriosos que nos evocan los ideogramas chinos, los garabatos de los niños o las pinturas rupestres en la época antigua.” Además, en 1948 "escribe" 200 dibujos. Sus letras son como ideogramas chinos, aunque ilegibles. Esto nos

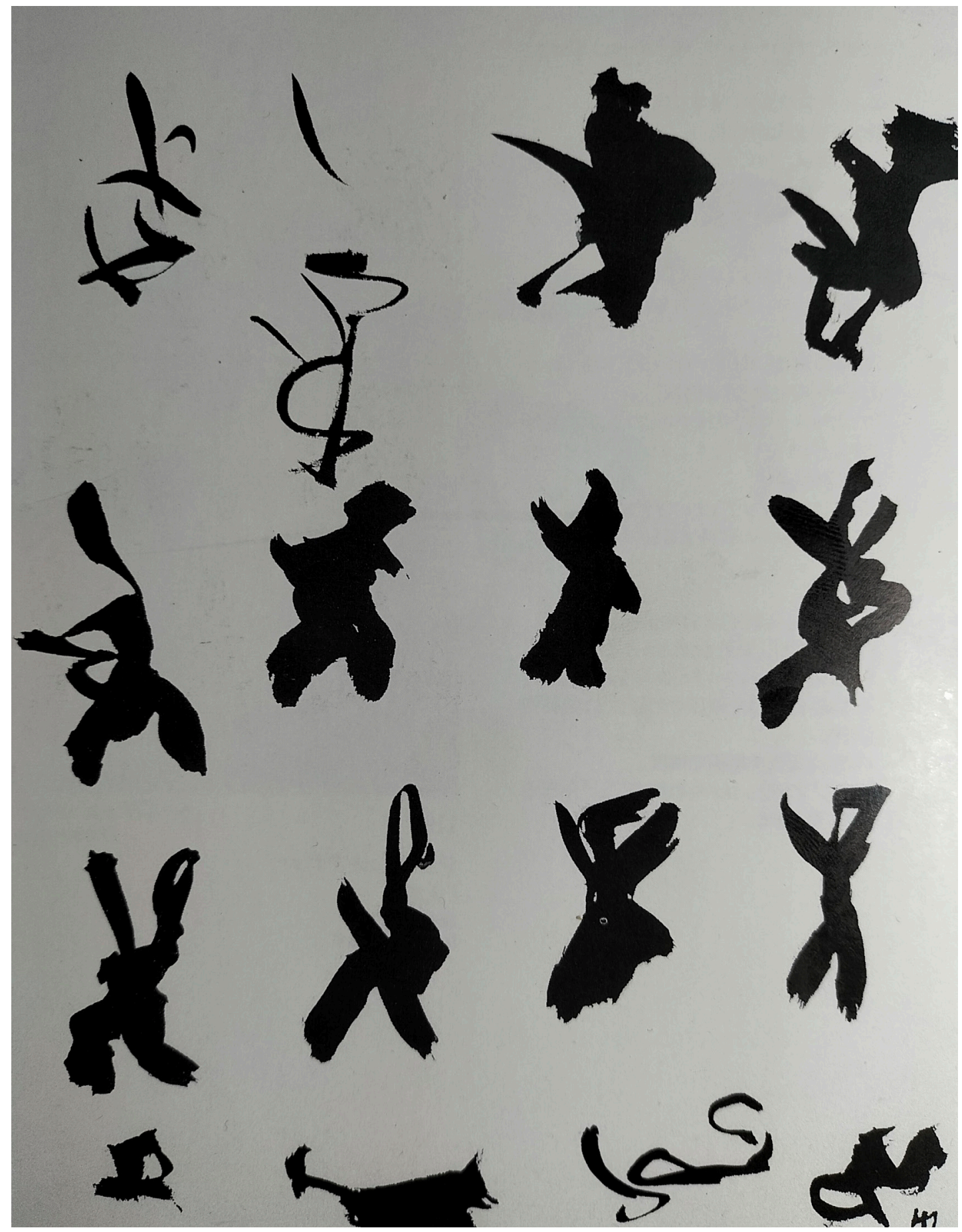

Fotografía 6. “Mouvement (Movimiento)" 1950, Kaneko Art Gallery 
incita a pensar que procede de su poema. En 1949 Michaux prologa la exposición de las primeras litografías de Zao, "(las obras) en la que circula el aire, el aliento de vida". Capta el carácter de su espacio pictórico "vacío" de esta manera. Para Michaux, quien ya había conocido el "vacío" en Japón, le resultaba muy familiar la belleza del "vacío" de Zao.

En 1950 Michaux llevó al marchante Pierre Loeb al taller de Zao. Loeb compró unos meses después una docena de lienzos y le propuso un contrato. Zao trabajó con Pierre Loeb desde 1950 hasta 1957. En el mismo año las ocho primeras litografías de Zao Wou-Ki, realizadas en 1949 en la imprenta Desjobert, expuestas en la Galerie La Hune, fueron publicadas por el escritor Robert J. Godet, acompañadas de ocho poemas de este último, formando un volumen titulado Lecture de huit lithograhies de Zao Wou-Ki escrito por Michaux, a quien Robert J. Godet había mostrado las obras de Zao. Por entonces, Zao y Michaux traban una amistad que perdurará toda la vida.

Simultáneamente se publica otro álbum de 6 litografías -Parí-Poemas-, con texto del escritor Harry Roskolenko. Después de esa experiencia, Zao constantemente trabaja con los poetas. Michaux entiende la esencia del arte de Zao -fundado en las estéticas chinas tradicionales-, por eso Michaux indica el año siguiente a Zao Wou-Ki que se ha perdido la exposición de Paul Klee en el Museo Nacional de Arte Moderno en París en 1948, y con ello, la posibilidad de conocer el arte del signo de Paul Klee en el viaje de Suiza de 1951. En realidad Zao, en cuanto vio el arte de Klee en directo, se convenció de que éste pintaba bajo la influencia del ideograma chino.

Se podría considerar que la colaboración de Michaux despertó en Zao la consciencia del valor de la poesía ideográfica y de la estética de coincidencia entre el poema y la pintura.

Después del trabajo con Michaux siguió conociendo a distintos escritores como Claude Roy, que fue poeta, crítico, novelista y, sobre todo, coleccionista de obras de Zao desde 1950, antes aun de conocerle personalmente. Claude Roy publicó la primera biografía del pintor chino en 1957 y en 1970 se hizo una nueva edición con prólogo de Henri Michaux. En 1967 Zao y Claude Roy publicaron un libro titulado L'Estampage Han por el editor Le Club Français du Livre, sobre la "pintura inscrita en la piedra". Para Zao este tema es la esencia genuina de la civilización china. Además, en los 60 y los 70 Zao trabajó en la ilustración de una serie de publicaciones con los poetas Arthur Rimbaud, Saint-John Perse, René Char, Jean Laude, Jean de Lescure y Roger Caillois, con lo que podemos afirmar que Zao Wou-Ki recuperó con ellos la coincidencia entre el poema y la pintura de la cultura china. Zao estuvo motivado por la colaboración con los poetas, pero la tradición china de coincidencia entre el poema y la pintura se mantuvo a lo largo de su trayectoria como manera de trabajo, incluso después de la desaparición del signo en la obra, transformándose en parte de la personalidad de su creación.

\section{ANDRÉ MALRAUX (1901-1976) Y LOS POETAS}

El novelista y ministro de cultura de Francia, André Malraux, que prestaba atención a la caligrafía oriental, conoció a Zao Wou-Ki a través de sus ilustraciones de La tentation de l'Occident, con 10 litografías, que se publicó en 1962. No es que Malraux despertara en Zao la estética tradicional china, pero el encuentro con este escritor es importante en la vida de Zao. El ministro ayudó al pintor chino a obtener la nacionalidad francesa en 1964.

En 1958 Zao había escrito el artículo El ensayo de un pintor chino que se nacionalizará francés para manifestar su sentimiento de gratitud a Francia, en la revista japonesa Geijutsu Shinchō, en Japón. Expresaba que el país que le formó como auténtico pintor había sido Francia, y reflexionaba sobre la vida que había pasado allí. Pero teniendo el tiempo que tardó hasta conseguir nacionalizarse francés, no es difícil imaginar que hubo muchos obstáculos y por eso fue determinante el encuentro con el Ministro de Cultura.

Aunque había llegado a la capital francesa dispuesto a abandonar su cultura natal, Zao se reconcilia con la cultura tradicional china a través de la amistad con los occidentales, aunque tuvo que batallar duro para conseguir que aflorara su propio lenguaje. París le ayudó a mezclar la cultura de Asia Oriental con la europea. Para el pintor chino, el tener la nacionalidad francesa será una manera de manifestar su agradecimiento a Francia. 
Como agradecimiento a André Malraux por su apoyo, Zao Wou-Ki realiza la obra "Hommage d'André Malraux" (200×525cm. 1976). En este momento salvo en algunas piezas de homenaje a personajes concretos Zao no ponía título a las obras. Estas solían llevar sólo la fecha de realización para que los observadores no reproduzcan la imagen concreta a través del título. La vida en la capital francesa fue definitiva para el desarrollo del arte de Zao.

\section{MARIA HELENA VIEIRA DA SILVA (LISBOA, 1908 - PARÍS, 1992)}

Esta artista portuguesa se instaló en París en 1928, donde desarrolló toda su carrera. Tras iniciarse como escultora, asistió a clases de pintura con maestros como Fernando Léger. Al declararse la Segunda Guerra Mundial se marchó a Brasil, donde permaneció entre 1940 y 1947. Allí trabó amistad con el pintor Joaquín Torres García, que se encontraba en Río de Janeiro participando en una exposición. La obra de Vieira da Silva es una obsesiva construcción de tramas lineales inspirada en ámbitos urbanos como pasadizos, bibliotecas o habitaciones, de larga perspectiva. Sus espacios son solitarios y laberínticos produciendo el efecto de dimensiones gigantescas, sin límite. Las piezas de la pintora consiguen generar una sensación de espacios envolventes; además, nos dan la impresión de que esos laberintos que crea con sus líneas no tuvieran fin. De regreso a Europa se convirtió en amiga de Zao y asistían juntos a la tertulia de la Galerie de Nina Dausset.

Cuando llega a París, Zao empieza a buscar la posibilidad de un nuevo espacio pictórico y, así, en 1951 empieza a reducir el paisaje a líneas muy finas, mientras que crea una perspectiva muy profunda, parecida al tratamiento de Vieira da Silva. Zao fue coleccionista de la obra de Vieira da Silva, por la que se sintió atraído cuando buscaba su propio estilo. El espacio pictórico expansivo de Vieira da Silva da a Zao Wou-Ki un impulso creativo evidente. En 1951 Zao realizó su obra "Piazza" y durante unos años pinta el paisaje con un estilo muy próximo al de Vieira da Silva. Reduce y simplifica las figuras en una construcción lineal y de perspectiva de ángulo amplia, pero la dimensión es compleja y un poco laberíntica, como si hubiera espacio de la tercera dimensión sin límite. Aunque no duró mucho la influencia del arte de Vieira da Silva en la obra de Zao, se podría decir que la pintora portuguesa y el pintor chino mantuvieron una interacción artística. La verdad es que ella es quien, como Michaux, recomendó a Zao conocer el mundo onírico de Klee, porque estaba impresionada por su tratamiento del espacio. El desplazamiento del interés de Zao de Vieira da Silva hacia Klee es coherente.

\section{PIERRE SOULAGES (RODEZ EN FRANCIA, 1919-)}

Pierre Soulages fue un pintor, grabador y escultor, amigo de Zao. No se sabe cuándo se produjo el primer encuentro, pero ambos eran miembros de la tertulia de la Galerie de Nina Dausset. Soulages es conocido como "el pintor del negro", porque realiza obras empleando sólo los trazos negros (Fotografía 7). A pesar de la diferencia del término de sus obras, compartían intereses comunes en el arte: la luz y el espacio. Por eso si contemplamos el concepto artístico de Soulages comprenderemos mejor el arte de Zao.

"En 1947 comencé a agrupar los trazos siempre largos de pincel (esas líneas eran desde el comienzo superficies coloreadas) en un signo legible de golpe, de manera rotunda. El tiempo del relato de la línea que sigue a la mirada, ese camino que tiene una duración era así suprimido. Desaparecida la duración de la línea, el tiempo se quedaba quieto con esos signos hechos con resumidos y directos golpes de brocha: el movimiento no se describe más, éste llega a ser tensión, energía en movimiento, es decir, dinamismo". ${ }^{1}$

Su obra presenta una materia densa con mucha masa, sobre la que el pintor hace surcos con el cuchillo: "a simple vista sólo el negro se extiende en su obra, pero este negro tiene diferencias de brillo, tranquilidad e intensidad." La luz se refleja en el negro y luego, de forma desigual, la superficie acepta la luz y produce el cambio sensible del tono del negro

\footnotetext{
Johnson. (1975: sin paginar).

2 Nihon bijutsu kyōkai, op, cit, (49).
} 


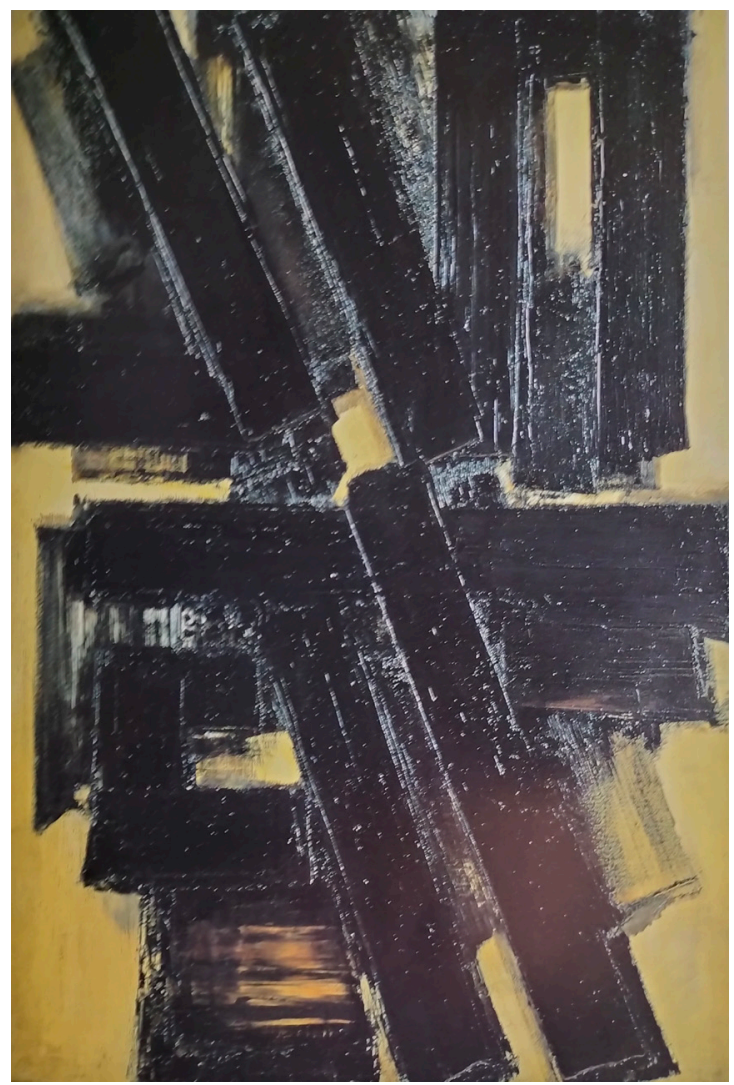

Fotografía 7. "Composition (Composición)" 1955, Gallary Garandou en un negro grisáceo o profundo. Cuando la luz se refleja en el negro, lo transforma y transmuta, por eso está obsesionado con este color. Para él el negro es la base de su paleta. No hay otro color más intenso, además da sentido a la presencia y fuerza de otros colores, incluso del blanco, "tal como un árbol convierte el cielo en azul (Soulages)", además, niega la posibilidad del negro para expresar el interior del pintor. $^{3}$

A primera vista el arte de Soulages se parece al arte informalista de Hartung o Mathieu, pero ellos sólo persiguen la huella del movimiento de las propias manos en el trabajo, en cambio en el arte de Soulages lo importante es que los trazos deben tener su propia materia para transmitir al observador. Además, la obra debe tener espacio innovador. Soulages explica, como conclusión, que a partir de la obra de Cézanne, se había cambiado el modo de abordar el espacio. ${ }^{4}$

Soulages, aunque muestra mucho interés por la caligrafía, las esencias importantes de su arte no son los trazos caligráficos, sino la luz y la coherencia del espacio pictórico. ${ }^{5} \mathrm{Y}$ estos temas son comunes a los que Zao trata en su obra.

Soulages, como buen amigo, apoyaba al pintor oriental tanto en lo profesional como personalmente. En 1957, después de que Zao viajara a Nueva York para olvidar el sufrimiento de la pérdida de su primera mujer por enfermedad, Soulages y su mujer le acompañan durante su recorrido por Washington, Chicago y San Francisco para visitar museos. Tras visitar Hawái los tres viajeros llegan a Japón para visitar Tokio, Kioto y Nara durante tres semanas. ${ }^{6}$ En Japón reciben numerosas invitaciones de artistas japoneses y participan en mesas redondas. En una mesa redonda donde participa Haga Tōru, el profesor de la literatura comparada, Soulages le muestra una comprensión profunda sobre el arte de Zao, comentando que ambos artistas tienen la misma preocupación: el espacio y la luz. Soulages menciona la luz mística que tiene que haber en la obra de arte, cuyo foco no es identificable exactamente, tal como le contó al pintor francés mismo George Duthuit, el amigo de los pintores y el historiador y crítico de arte que publica en 1936 un libro de la relación entre el zen y las pinturas occidentales, Mystique chinoise et peinture moderne. ${ }^{7}$ Soulages encuentra esta luz en la iglesia románica de su

3 Cita extraída de la explicación del propio pintor al historiador de arte Pierre Schneider. Además, le cuenta la experiencia del contraluz en el negro en la época de Bellas Artes. Sobre el negro, dice: "No hay sentimentalismo alguno en mi gusto por el negro. En China, el negro no es el color del luto. Simplemente veo el negro” (Soulages). Johnson James (1973: 13, 14)

4 Soulages, Zao y Haga (Mesa redonda) (1958 (03): 26).

5 Soulages mismo manifiesta la opinión sobre la similitud entre su arte y la caligrafía de manera siguiente en la mesa redonda con Zao Wou-Ki y Haga Tōru. Un carácter de la caligrafía tiene un sentido tal como $\otimes$, que significa flor, tiene una estructura también como escritura, tiene también la fonética y por último la letra de la caligrafía debe tener la personalidad propia del calígrafo, por eso para el pintor francés su arte es bastante distinto a la caligrafía. Sobre la estructura de la letra, el presentador crítico de arte Haga Tōru piensa que Soulages considera que la caligrafía tiene el factor de la pintura figurativa. Zao Wou-Ki está de acuerdo de ellos. Dice que los japoneses y los chinos pueden evocar el objeto "flor" al ver el ideograma en chino o en japonés. Pero Haga Tōru propone que hay algo más en la letra que el factor figurativo, que la letra sugestiona más, igual que la letra $\otimes$ inspira a los japoneses su olor. Ibidem, (26).

6 Marquet (1980: 310).

7 Zao Wou-Ki recuerda bien a George Duthuit y escribe que le enseñó la grandeza del arte románico y del arte bizantino y que además discutían mucho sobre la tradición china. Zao op, cit, (38). 
pueblo natal. ${ }^{8}$ La importancia de la luz se identifica también con la importancia del espacio. ${ }^{9}$

Zao Wou-Ki también experimenta la luz de la iglesia. Zao viaja a Italia en junio de 1951.

Va primero a Toscana, luego a Roma, Pompeya, Nápoles e Ischia. Descubre en estos viajes muchos espacios en los que las perspectivas cambian ante el ojo del observador, como sucede en la pintura china. ${ }^{10}$ Además, le gusta la excursión por Bourgogne o el oeste de Francia para visitar las iglesias y las catedrales. Las esculturas de los capiteles de las fachadas le transmiten, con la luz mística, un aire tranquilo e íntimo. "como si le invitara a entrar en ella, pero de manera muy espontánea”. ${ }^{11}$

Estas anécdotas nos cuentan que Zao se preocupaba mucho por el espacio y la luz mística en su arte y que comparte con Soulages un mismo objetivo en el trabajo. El pintor francés y el chino crean la sensación del espacio con un ambiente sagrado. Soulages muestra una admiración por Zao. El hecho de que Zao sea coleccionista de las obras de Soulages nos invita a creer que estuvo interesado por el sentido del espacio de Soulages. ${ }^{12}$

\section{CONSIDERACIONES FINALES}

Hemos investigado cómo los principios chinos tradicionales despertaron en el interior del artista chino Zao Wou-Ki en su contacto con la cultura europea, si bien el pintor llegó a Francia para intentar escapar de la restricción de las tradiciones por el convencionalismo de su tierra natal. Lo que le ocurrió a Zao fue que, lejos de abandonarlas, recuperó sus raíces e introdujo la estética china en su obra de manera paulatina. A través de las colaboraciones, los diálogos y las actitudes de los amigos pintores contemporáneos de Zao, hemos podido entender mejor la estética china tradicional que él recuperó.

Sobre el ejercicio ideográfico, proponiendo la hipótesis de que en las obras de Zao aparece la coincidencia entre la pintura y el poema, hemos investigado las relaciones con los poetas, sobre todo con el buen amigo Henri Michaux, porque el poeta comprende los caracteres del arte de Zao ya antes de trabar amistad con él. Además, fue él quien empujó al pintor chino a conocer el arte del signo de Klee. Después de colaborar con Henri Michaux, Zao empezó a realizar trabajos con numerosos poetas. En el proceso de la evolución de su arte, Zao dejó de pintar signos en su obra, pero siguió trabajando con poetas y de un modo poético. En China, bajo la estética coincidencia entre la pintura y el poema, el trabajo en relación con los poetas nunca significa que las pinturas sean complementarias de los poemas. Henri Michaux, un pintor que había viajado mucho por Asia debió de intuir el carácter oriental del pintor chino al observar sus obras, tal como escribe en 1952 en una presentación para el catálogo de la exposición de Zao Wou-Ki en la Hanover Gallery de Londres y la Cadby Gallery de Nueva York. ${ }^{13}$ Teniendo en cuenta su viaje por Asia y su trabajo como caracteres chinos, sin ninguna duda entendió la esencia del arte de Zao. Después de la colaboración con Henri Michaux, Zao dedica constantemente sus obras a poetas, contemporáneos o clásicos, por

8 Daniel Abadie indica que el arte de Soulages tiene el carácter nostálgico de los viejos tiempos. "A partir de 1950 la pintura se aplicó como una fina película sobre el grano del lienzo, revelando en algunos puntos su estructura y dando así la impresión de que el color no lo cubría completamente y el soporte lo había abortado, como si se tratara de una obra muy antigua. Esta tendencia a la aclamación era característica de la época. En efecto, los pintores de la Escuela de París intentaron volver a lo más granado de la pintura francesa, pues mientras unos analizaban las estructuras de la arquitectura románica (Soulages) o los esmaltes del Lemosín (Lapique), otros se interesaban apasionadamente por los frescos de Tavant (Bazain) y las vidrieras góticas (Manessier), como si, más allá de la tradición del Renacimiento y de su concepto de la perspectiva, lo que intentaran fuera tomar de nuevo contacto con un arte que nunca había conocido la decadencia académica. En el caso de Zao Wou-Ki, este deseo de volver a las fuentes originales debía expresarse de otra manera. En efecto, Jena Leymarie ha señalado con acierto que estos colores sugieren el "refinamiento del material y del colorido", el "grano aterciopelado" de la porcelana del periodo Song. En cuanto a su dibujo, excusado con la punta del pincel fino, que preside su obra, sus elementos narrativos recuerdan a las figuras de los ladrillos sigilados de la dinastía Han, cuyo carácter abocetado se ve compensado por el poder evocador de las concisas anotaciones." Abadie (1989. 10), Marquet y Hendgen (2004: 187).

9 Soulages sobre el jardín seco del templo Nanzen-ji afirma: "Expresa que el espacio envuelve espontáneamente a los espectadores, que los espectadores entran en ella y vive allí inconscientemente.” Soulages, Zao y Haga (Mesa redonda), op, cit, (30).

10 Marquet, op, cit, (1980, 310).

11 Zao Wou-Ki, op, cit, (38). Zao mismo escribe sobre el viaje de Bourgogne, "Aunque Duthuit no me recomienda hacerlo, ...”. Esta expresión sugiere que Zao es muy consciente de la idea de la luz y del espacio de Duthuit.

12 Zao Wou-Ki coleccionaba también las obras de Hans Hartung, Gerard Schneider, Jean René Bazaine y Maria Helena Vieira da Silva. Martine Contensou explicaba que Zao ponía cierta distancia a estas obras para tener el estilo propio, pero otra cosa es que lo consiguiera, ya que hemos contemplado las afinidades manifiestas con varios de ellos. Contensou (1989: 22),

13 Michaux no aceptaba ninguna solicitud de otros artistas contemporáneos aparte de Zao. Leymarie (1980. 20). 
consiguiente, podremos decir que despertó a Zao el concepto coincidencia entre el poema y la pintura. Sus colaboraciones con los poetas nos recuerdan que, tradicionalmente en China, se considera que la pintura y el poema tienen la misma raíz, tal como el fenómeno de escribir el poema en la pintura. En China, ambas son artes admirables, por eso Zao debió de trabajar con orgullo para los poetas.

Por otro lado, sobre la tradición del qui merece la pena fijar la atención en María Helena Veira da Silva y Pierre Soulages. Vieira da Silva es una de sus amigas que entendía la esencia del arte de Zao. Una temporada Zao intenta captar el nuevo espacio en la obra de Vieira da Silva, pero Vieira da Silva le aconseja conocer el arte de Klee, aunque considero que el interés por Klee de la pintora es el tratamiento del espacio expansivo, mientras que el de Michaux es el signo de Klee. Así Zao tuvo la oportunidad de evolucionar artísticamente. Se ve claramente que los pintores amigos también se encargan de despertar las raíces en la mente de Zao.

Igualmente concluimos que es muy importante Pierre Soulages para entender la estética de Zao, porque compartía con él la idea del espacio y la luz. Aunque es cierto que Zao interpreta el espacio de Klee para transformarlo en su estilo propio, el pintor francés y su obra estimularon al pintor oriental. En realidad, Zao y Soulages muestran el interés por la idea del espacio con la luz mística propuesta por George Duthuit, cuyo foco es invisible. A primera vista, ambos pintores pintan como informalistas, poniendo muchos trazos para transmitir el movimiento, pero en realidad, quieren crear el espacio sagrado tridimensional con la luz sagrada, es decir, un nuevo espacio pictórico sin el recurso de la perspectiva tradicional. Por eso, aunque sus obras superficialmente son distintas, sus conceptos coinciden. Después de leer los diálogos de Soulages, entendemos que a Zao le interesa crear el espacio. Zao siempre pintaba el espacio lleno de energía visto a través de la luz y el viento.

Como hemos visto, a través del análisis del arte o de los diálogos de los pintores amigos de Zao, se puede entender más profundamente la estética tradicional china presente en la obra de Zao Wou-Ki. 


\section{BIBLIOGRAFÍA}

- Abadie, D. (1989). Zao Wou-Ki en Zao Wou-Ki, Barcelona: Polígrafa. 7-18

- Barmann M. (1998). Klee en Túnez: la peregrinación a las fuentes en Paul Klee, Valencia: Instituto de Valencia de Arte Moderno. 53-67

- Bascón Maqueda M. (2013), Maria Helena Vieira da Silva. La obra de la artista a través del conocimiento de su vida, Sevilla: Padilla Libros editores \& Libreros. 156, 162

- Cheng F. (1981), Zao Wou-Ki ron en Zao Wou-Ki ten: Aburae to sumie. Tokio: Kokusai bunka kyōkai. sin página

- Contensou M. (1989) Life into work en Zao Wou-Ki: Barcelona: Polígrafa, 19-32

- Fréches J (2007), La inspiración y el alma, en Zao Wou-Ki. Obras/Escritos/Entrevistas, Barcelona: Polígrafo. 9-79

- Fernández Molina A. (1980). Henri Michaux, realización de lo visionario en Henri Michaux. Zaragoza: Caja de Ahorros y monte de piedad de Zaragoza, Aragón y Rioja. 11-13

- Gállego J. (1991): "Penélope e Helena” en Vieira da Silva. Madrid: Fundación Juan March. 11-17

- Fernández del Campo E. y Sanz Giménez S en Arte chino contemporáneo: San Sebastián

- Frontisi C. (1998). Klee en Túnez: la peregrinación a las fuentes en Paul Klee, Valencia: Instituto de Valencia de Arte Moderno. 39-52

- Guion, E. (2001) Trayectoria de Zao Wou-Ki en Zao Wou-Ki. Valencia: Institut Valencià d'Art Modern, 11-17

- Herbert R. (1984). La historia de la pintura moderno. Barcelona: Ediciones del Serbal

- Huser F. (2001). “La conquista de la luz”, en Zao Wou-KI. Institut Valencià d'Art Modern Valencia, 18-24

- João Fernandes M. (1991) A pintura de Vieira da Silva: Cintilações e sóis en Vieira da Silva. Madrid: Fundación Juan March 18-26

- Jean-Clarence, Lambert. (1991) "Sugai”, Barcelona : Polígrafa.

- Johnson Sweeney J. (1972). Pierre Soulages, en Soulages Neuchatel: Ides et Calendes, 5-29

- Johnson Sweeney J. (1975). Pierre Soulages en Soulages Salas de exposiciones de la dirección general del patrimonio artístico y cultural. Madrid: Patrimonio artístico y cultural, sin página

- Lambert, Jean-Clarence, Sugai, Barcelona: Polígrafa

- Leymarie J. (1980). Zao Wou-Ki, Barcelona: Polígrafa.

- Marquet F. (documentación) (1980). Biografía. en Zao Wou-KI. Barcelona: Polígrafa. 308-312

- Marquet F. y Hendgen, Y. (2004). “Nenpu” (córnica personal), en Zao Wou-Ki, Breadgestone Museum, Tokio, página 183-193

- Maspero H. (2000). El taoísmo y las religiones chinas. Valladolid: Simancas

- Nakamura, N. (1994). Tōzai bijutsu-shi. Tokio: Iwasaki bijutsu-sha

- Nihon bijutsu kyokai (una asociación de arte). (1999) Art of our time: Takamatsu no miya denka kinen sekai bunka-sho no 10nen. Tokio: Nihon bijutsu kyoukai

- Ōoka M. (1983). Henri Michaux -Sonzai no arufabetto no tankyū, en Henri Michaux ten zuroku, Tokio": Seibu bijutsukan, 18-24

- Pacçuement A. (1989). Henri Michaux, realización de lo visionario en Henri Michaux, Zaragoza: Caja de Ahorros y monte de piedad de Zaragoza, Aragón y Rioja. 7-8

- Pellegrini A, Nuevas tendencias en la pintura, Muchnik editores, Buenos Aires, 1967, 73.

- Soulages P., Zao W. y Haga T. (1958(03)). (Mesa redonda), Souzō to dentō en Sansai (97). 20-31

- Preciado Idoeta I. (2006). Los libros del Tao. Tao te ching. Madrid: Torotta.

- Ragon M. (1962). Bi no zenè tachi. Tokio: Bijutsu shuppan

- Ragón M. (2007). Entrevista con Zao Wou-Ki en Zao Wou-Ki. Obras/escritos/entrevistas. Barcelona: Polígra. 101-119

- Takiguchi S. (1955). Abusutorakuto a-to undō - sho to gendai kaiga en Shodō kouza7 Gendaibun Zenei-sho, Tokio: Nigen-sha, 82-86

- Ucciani L. (2001). Zao Wou-Ki en "Zao Wou-Ki”. Valencia: Instituto Valencia del Arte Moderno. 25-37

- Westgeest H. (1997). Zen in the fifties: interaction in art between east and west. Zwolle y 
Amstelveen: Wannders Publishers y Cobra Museum voor modern kunst.

- Zao W. (1958(03)). Fransu ni kika suru chūgoku gaka no shuki. Geijutsu Shinchō, 9, 31-41

- Zao W. y Marquet F. (2004), Autoportrait, Faryart,

- Fotografìa

- Fotografía 1-5 : Burijiston bijutsukan (edición). (2004), Zao Wou-Ki, Inshō-sha.

- Fotografía 6, 7 : O bijutsukan (edición). (1992). Sho to kaiga tono atsuki jidai. 1945-1969. Inshō-sha. 